\title{
Assessment of Continuous Wet Day Rainfall Frequency Distribution in the Intermediate Zone of Sri Lanka
}

\author{
Jayasuriya M.T. and Najim M.M.M.*
}

\author{
Department of Zoology, Faculty of Science, University of Kelaniya, Kelaniya, Sri Lanka \\ *mnajim@kln.ac.lk
}

\begin{abstract}
Changes in rainfall distribution patterns around the world have caused fluctuations in those climate regimes. Agriculture is particularly vulnerable to climatic conditions and it is chief among the systems that are expected to undergo changes as a consequence of climate change. This study analyses the climate change variability through the fluctuation in precipitation pattern and evaporation, in low country intermediate zone $\left(\mathrm{IL}_{1 \mathrm{a}}\right)$ agro ecological region based on Gumbel's frequency distribution analysis on wet day rainfall data. Focusing on a cascade agricultural system in the Katupotha divisional secretariat division of the Kurunegala district that is located in the $\mathrm{IL}_{1 \mathrm{a}}$, the climate change variability was analysed using daily rainfall data of fifty years (1961-2010) together with long term evaporation data. Experimental methodology considered a day to be wet only if the rainfall exceeded its evaporation. This was considered as the precipitation amount that could potentially be used by the crops.
\end{abstract}

Gumbel's frequency analysis was employed to derive the variability in continuous wet day rainfall distribution at 25 year time intervals (1961-1985 and 1986-2010). The total continuous wet day rainfall and seasonal total continuous wet day rainfall frequency distributions were analysed using the technique. Results of the analysis show an increasing trend in magnitude of the total continuous wet day precipitations from 1961-2010. This increasing trend is observed beyond 2.2 years recurrence interval. At longer recurrence intervals (20 years) a $50 \mathrm{~mm}$ increase is experienced during the last 25 years (1986-2010) while at shorter recurrence intervals ( 2.2 years), a $6 \mathrm{~mm}$ increase is evident. A distinct increasing trend in the total continuous wet day precipitation from 1961-2010 was observed during the second inter-monsoon which was a $165 \mathrm{~mm}$ increase at a 10 year recurrence interval. In contrary, the south-west monsoon, first inter-monsoon and north-east monsoon recorded decreasing trends in the total continuous wet day precipitation from 1961-2010.

Keywords: Gumbel's distribution, Wet day, Recurrence interval, Climate change 